\title{
Promoting sustainability of earth constructed private and public buildings in South Africa
}

\author{
G. Bosman \\ Unit for Earth Construction, Department of Architecture, \\ University Free State, South Africa
}

\begin{abstract}
For many urban South Africans the traditional way of building recalls rustic images with a colourful cultural past. The self-help process of home-making in traditional materials is still strongly linked with rural earth construction. While the temporary recycled shack becomes the next housing step closer to the image of the promise of a better life in the city.

In South Africa the ever growing consciousness of sustainable values resulted in some long life, low energy and lose fit buildings constructed during recent years. This paper reflects on some buildings constructed, sustainable efforts in capacity building and training on different levels during the past ten years under the supervision of the Unit for Earth Construction (UEC) at the University of the Free State. These activities of the UEC shows that by upgrading existing skills and techniques involving stabilised earth construction, economic and ecologically sustainable buildings of a high quality can be built. The social and cultural sustainability of these buildings boost local economic development and can help to revive the tradition of women participating in the home-making process. Much of the findings in this paper are based on desktop research, field studies, involvement in community buildings and the personal experience of the author in building his own home using a considerable amount of earth construction. This paper also reflects on preliminary findings from a research project funded by SANPAD (South Africa - Netherlands Research Programme on Alternatives in Development) and conducted by the University of the Free State in collaboration with the Technical University Eindhoven, Netherlands.

Keywords: sustainable development, earth construction, training, community small builders, professionals, architecture students.
\end{abstract}




\section{Introduction}

In years to come, South Africa will have to cope with the huge shortage of affordable, human and comfortable housing for its inhabitants. Against the background of a colourful history of vernacular architecture and an elaborate colonial European image, the poor will continue building temporary urban shelters constructed in rubble plastic and discarded wood and corrugated iron.

High expectations from sensitive, controversial [7] and some times corrupted government housing projects, the loss of indigenous building practices, and the elusive prosperous city life contributes to an unwanted built environment [2].

The preferred building materials in South African informal settlements are mainly lightweight, recycled material. Together with rapid urbanisation and the occasional overnight relocation of these settlements, make the structures' intransit adaptability by far more favourable than its comfort or safety. Few city dwellers will resort to a traditional way of building, if so, it is seen as temporary. Even if natural building materials like suitable earth for construction, wood, grass or stone are available, the image of building in natural material is not acceptable. Changing aspirations and loss of knowledge also result in poor use of natural materials, reducing the status of traditional buildings.

There is a constant struggle between the simple and frail African technology, supported by subsistence lifestyle with natural rules and the changing new technologies with no sustainable principles in mind. Exploited for centuries, African cities were conceived, designed and built on European models, which eventually supports an American life style [8].

\section{Earth construction as vehicle for sustainability}

During the past 10 years more than a thousand students have been trained by the UEC in the advantages of the contemporary application of earth construction techniques. These young professionals have begun to reach the market place effectively, gradually eroding some misconceptions and scepticism pertaining to earth construction in general. Architects should not only design earth constructed and sustainable buildings, but build and inhabit it as well, for they are in the position to introduce new materials and construction techniques with in their designs. The character of the soil in the Free State [7], the vernacular architecture and the climate allow suitable use of both adobe (sun dried earth blocks) and CEB (compressed earth blocks).

The energy crisis of the 70's only resulted in government endorsed projects in the 1980's, where European building projects became prototypes of energy saving and environmental friendly construction techniques. In the early 90's South Africa, with the support from several European Organizations, persisted in the quest to challenge a more technical, scientific and systemic approach to building with earth. 

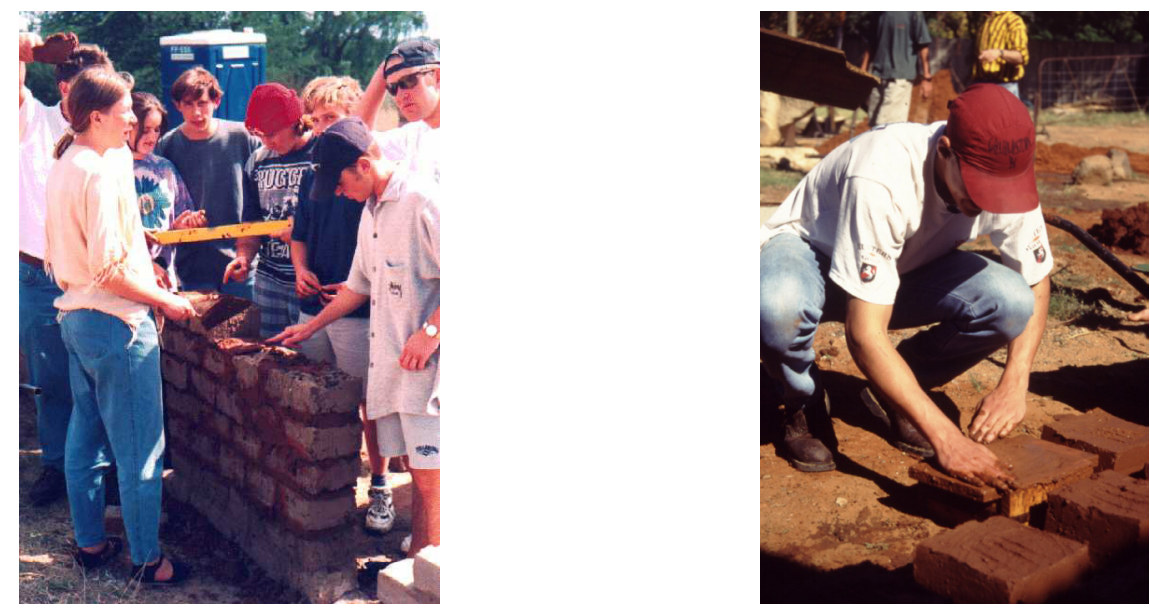

Figure 1: Students doing service learning classes on community projects in the production and construction of adobe or sun dried earth blocks.
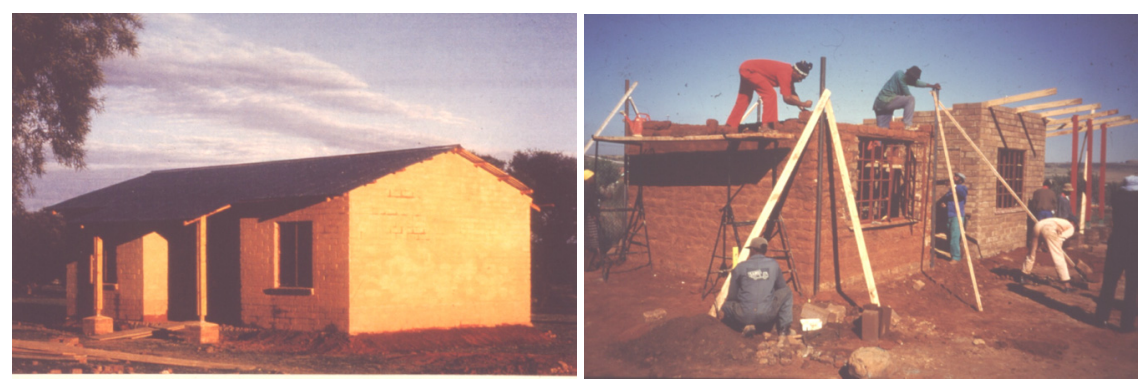

Figure 2: A Proto-type farm workers house at Glen Agricultural College, Bloemfontein and the Albert Luthuli Day Care Centre in Mangaung during construction in 1997 [3].

\section{Training of young professionals}

The University of the Free State was in the fortunate position to become one of a few tertiary institutions world wide to include a scientific based education programme with earth construction as part of the curriculum. The Department of Architecture is the smallest, of the six national Schools of Architecture, with between 180-200 students annually. The design programme of the school is founded on the "making of meaningful place" a universal theme being propagated by Christiaan Norberg-Schulz [10] since the 1980's in Genius Loci: Towards a Phenomenology of Architecture.

The Unit for Earth Construction (UEC) was established at the Department of Architecture in 1995. Core objectives of the UEC have been to gain experience through building projects, developing building capacity and reaching out to 
communities in the area surrounding Bloemfontein, the capital of the Free State Province. Architecture students in their first to fourth years are being trained by the UEC by means of an Integrated Sustainable and Alternative Development Programme with the vernacular and rural landscape as background. In each year, 3-6 weeks are dedicated to design projects which focus on (i) earth construction techniques, (ii) climate control, (iii) appropriate structural systems, and (iv) recycling of building material and structure [2]. Training of not only Architecture but also Quantity Surveying and Construction Management students, established the Unit for Earth Construction (UEC) as one of the leading institutions in Africa [1].

\section{Training of community builders}

The UEC has focused on training on different levels. The completion of 8 small to medium buildings completed since 1996 gave the opportunities for training small scale community builders. The cooperative and collective patterns of organized labour [11] are a well established custom in South Africa. Between 1996 and 1999 a prototype farm workers house, two humble day care centres and 3 ablution blocks were constructed with lime plaster adobe and compressed earth blocks.

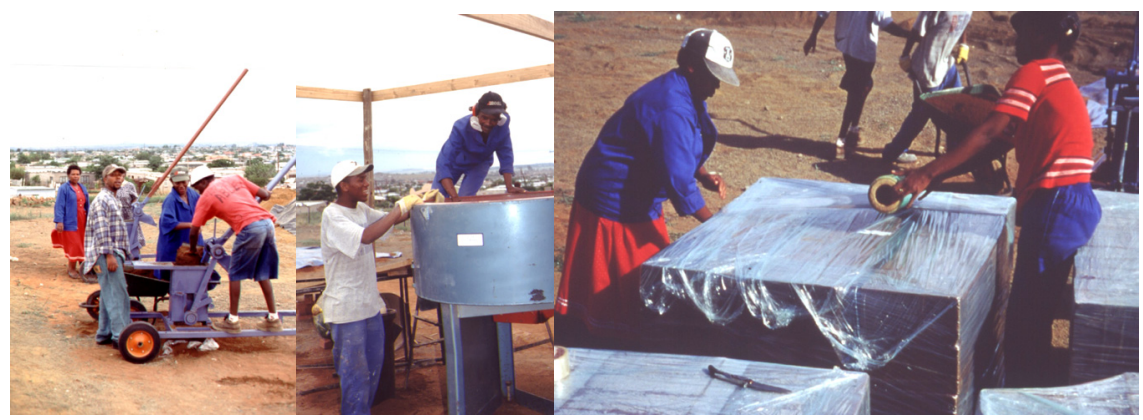

Figure 3: Brickyard activities in 2002 at the Mangaung University Community Partnership Programme (MUCPP) in Bloemfontein [3].

Between 1999 and 2005 an economic development centre, a school hall and a craft and tourism centre was constructed with the help of the UEC. Through these projects 170 male and female small builders have been trained in the production and construction of either adobe or compressed earth blocks. The staff of the UEC (two colleagues and the author) has been part-time involved in all of these projects dividing time on site and lecturing duties at the Department of Architecture.

During the past projects the UEC has learnt a lot from the expectations of communities. Many of the community training programmes since 1996 that focused on the production and construction with earth components have been 
greeted with great enthusiasm and commitment but resulted in only a few small brickyards becoming sustainable. New groups with no business financial history always have problems establishing small loans. Often these discouraged trainees and beneficiaries have moved on to greener pastures - leaving few survivors behind [2].
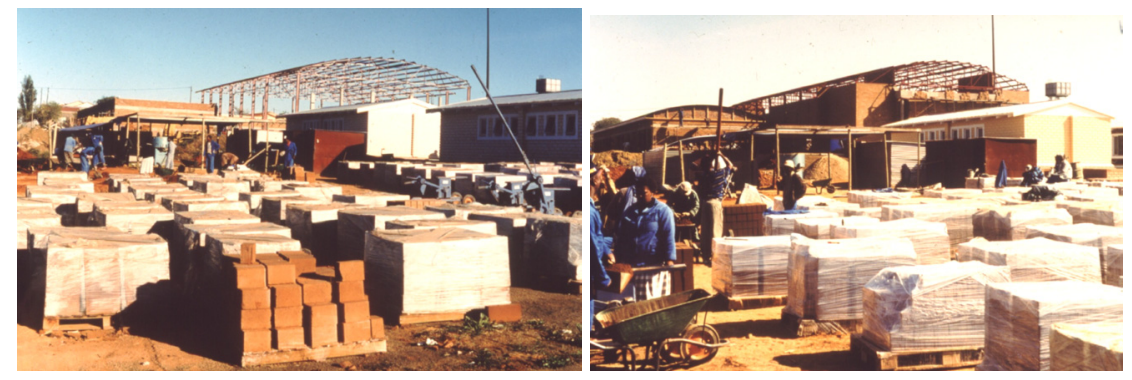

Figure 4: MUCPP-brickyard activities with the Economic Development Centre in the background, 2000-2002 [3].
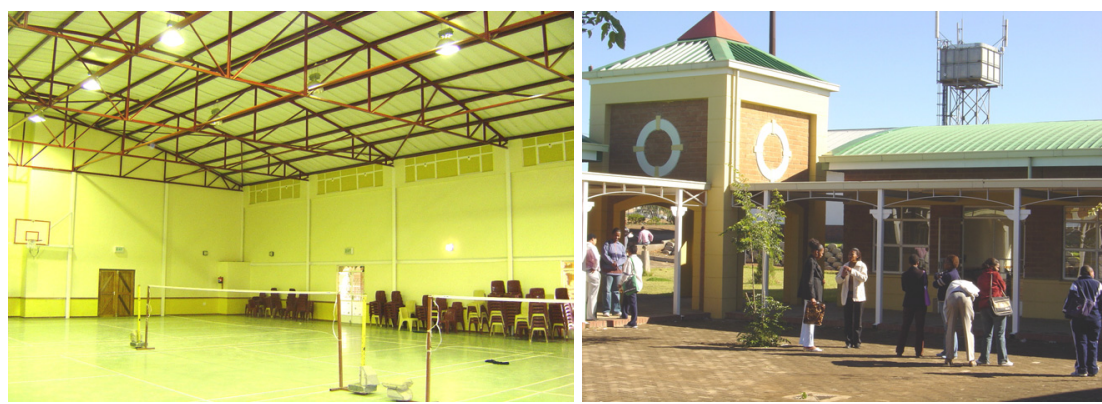

Figure 5: MUCPP-activities in 2005 at the Economic Development Centre, Mangaung, [3].

In South Africa there is a growing awareness to test a building's sustainability regarding social, economic and environmental aspects. The Sustainable Building Assessment Tool (SBAT) is a South African developed system used by the Council for Scientific and Industrial Research (CSIR), Academic and Technical Universities in South Africa. This also proofed to be a useful tool for architects, building managers and informed public addressing sustainable issues [14].

\section{Sustainable environment versus economic development: the struggle for survival}

The difficulty for communities to manage and maintain buildings is a common phenomenon in South Africa. It is almost impossible for these communities to contribute time, labour, and imagination to the management and maintenance of community facilities. In most cases the communities, especially in poverty 
stricken rural areas, are poor and cannot achieve these aims with limited resources. In addition, many people hold the view that support from the government is mandatory as part of the process of income re-distribution that has been promised for years [9].

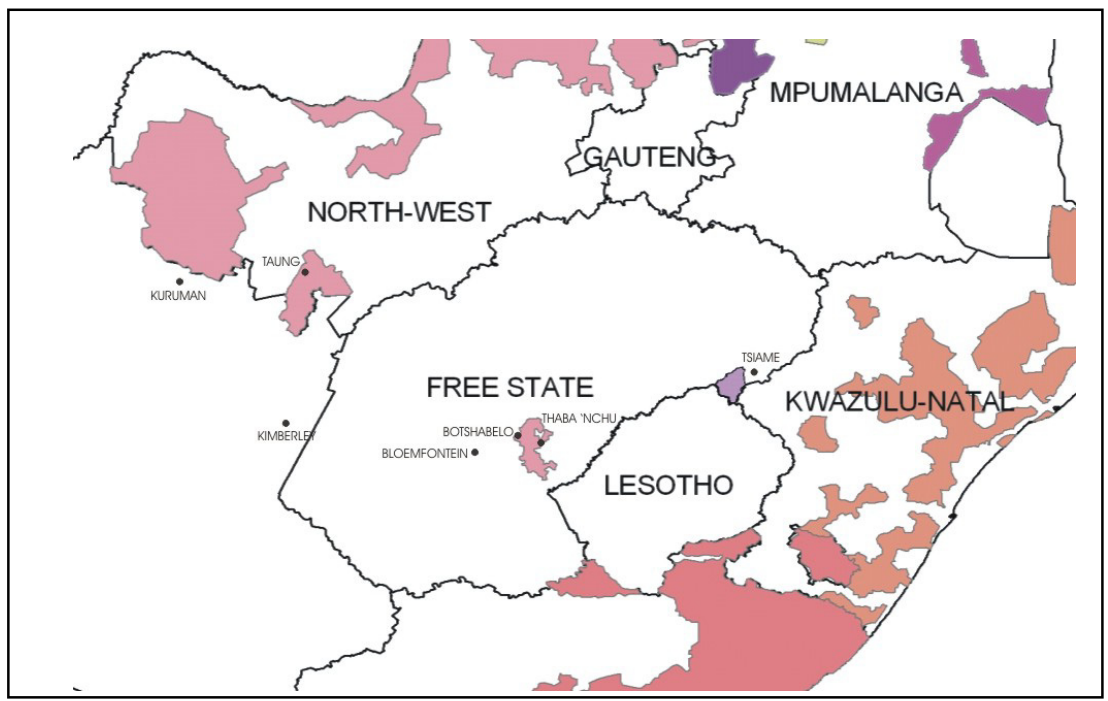

Figure 6: The five different research areas of the SANPAD project.

The UEC is currently in the third year of a research project funded by The South Africa Netherlands Project on Alternative Development (SANPAD). The title of the research project is: A South African Building Renaissance Acceptability of sustainable, high quality, earth constructed, public and private buildings to support local sustainable economic development. Seven locations in five different research areas (north east of Bloemfontein and north west of Kimberley), all nearby former homelands, have been targeted in the Free State, North-West and the Northern Cape Provinces.

A Survey was conducted with Questionnaire 1 (with a total of 1800 participants) on the acceptability of earth constructed houses within this mainly rural environment. We can confirm that the general public mostly prefer burnt brick walls for their own houses. The main reasons: "It looks good! The Material is strong and safe".

The people (78.2\%) that live in an earth constructed house claimed to have made the blocks themselves, with the help of a friend or a family member while $21.8 \%$ paid for it. Of the 9 semi-formal and 13 informal brick yard owners in these research areas, producing mainly cement stabilized concrete blocks or substandard burned clay bricks, $90.6 \%$ will be interested in learning to produce other kinds of bricks or blocks. It is clear that there is a need to expand the type of products in these brickyards. These brick yard owners (96.9\%) confirmed that they also would be interested to attend workshops in order to learn how to make 
compressed earth blocks (CEB) and stabilized adobe. The training in technical and management skills of this local trades can increase the number of blocks and bricks produced, which currently varies between 2500 and 15000 blocks per person per month, with at total number of bricks and blocks at 387000 per month [12].

Table 1: The question results on the SANPAD Questionnaire 1: Choose the two materials you prefer most for building your walls.

\begin{tabular}{|l|l|l|}
\hline Material indicated & First choice & Second choice \\
\hline zinc & $6.0 \%$ & $5.0 \%$ \\
\hline bricks & $\mathbf{5 9 . 6} \%$ & $\mathbf{3 2 . 7} \%$ \\
\hline cement blocks & $\mathbf{2 9 . 6 \%}$ & $\mathbf{5 2 . 9} \%$ \\
\hline adobe & $3.2 \%$ & $3.9 \%$ \\
\hline wood & $0.0 \%$ & $0.0 \%$ \\
\hline wood \& earth & $0.0 \%$ & $0.6 \%$ \\
\hline
\end{tabular}

The UEC will complete workshops with a follow up survey, by July 2006 in these areas, targeting decision makers (traditional chiefs, councillors, small builders and brickyard owners) and present an outreach community theatre production to school children and the public at large. This dramatized performance will reflect on the low status of traditional earth building and focus on the many advantages of living, and building your own house in an upgraded eco-friendly earth building technique.

The main research question to be answered is: How can earth construction be more effective and acceptable in providing private and public buildings to local communities in support of sustainable economic development? During the dissemination of this project it should be clear if a technological intervention in the form of training can make and impact on the acceptability of earth constructed buildings. If the local brick yards in these areas can provide new improved earth products, it can change the acceptability of earth building in these areas.

\section{Sustainable thinking}

Working with earth as the primary tool to promote sustainable thinking, results in various problems. These problems with earth buildings can be grouped under the following:

1) Mechanical performance

2) Standardisation to comply with local authorities and financial institution

3) Social acceptability (high expectation) [3]

The combined knowledge of experienced scientists, soil technologists, builders and architects, gained over the last three decades, contributes to the increased utilization of earth. The mechanical performance of earth used for 
construction will be in question for years to come. Convincing publications on this issue not only helped the scientific community to take stock of this area of study, but also react to the high expectations of the non-scientists' desire to understand the issues [6]. Earth construction was prohibited in of the South African towns and cities as a result of by-laws and conditions for loans set by financial institutions. This resulted in earth construction being reduced to mainly rural areas. However earth construction made a comeback after the Second World War when it was again extensively applied by many farmers who either knew the techniques of earth building or learnt them anew [5].
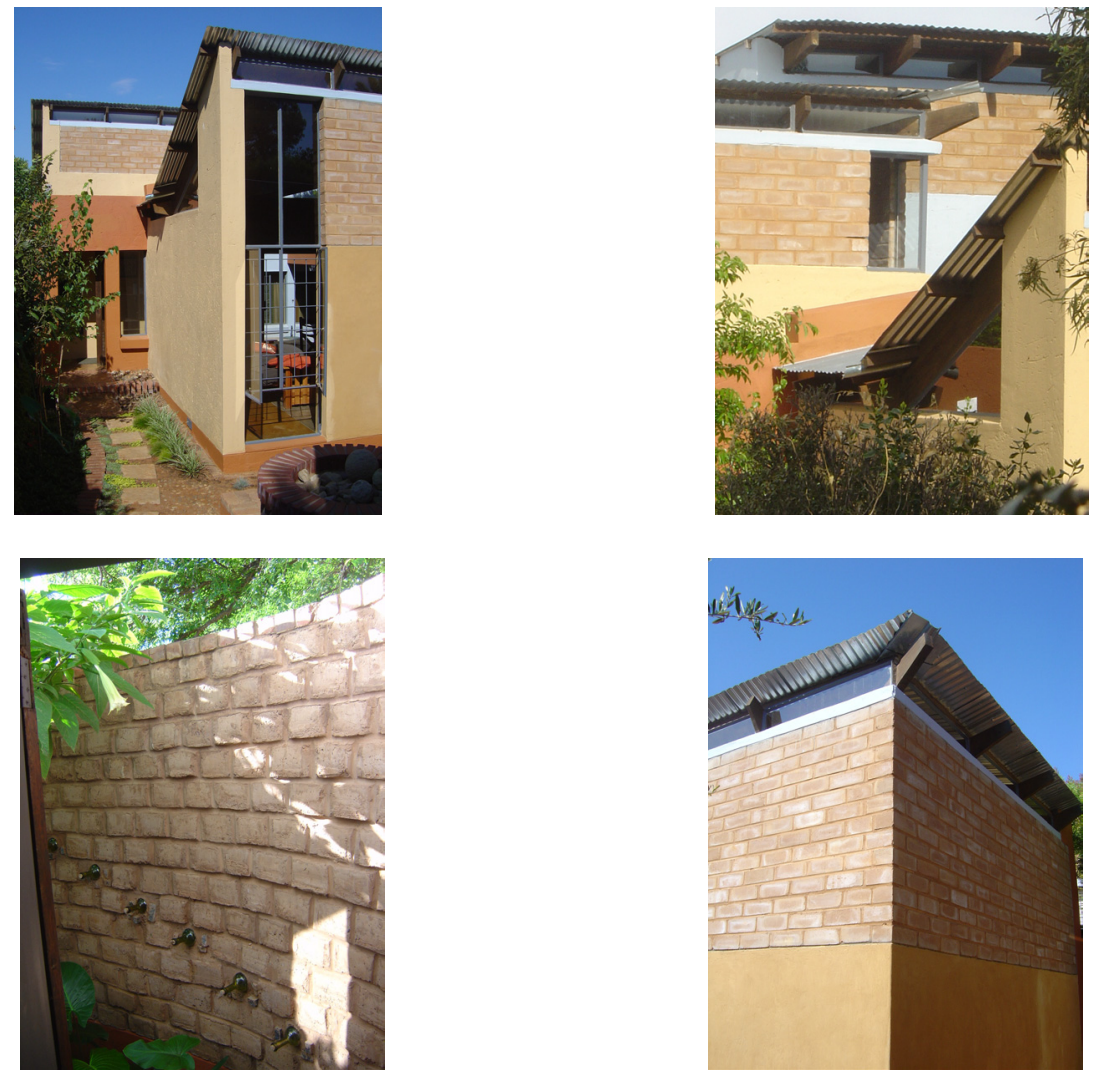

Figure 7: Bosman Residence with the application of stabilized adobe and compressed earth blocks in the residential area of Westdene, Bloemfontein.

Unlike many other developing countries and some European countries, South Africa still does not have national standards for Earth Construction. However approval for earth building systems can be obtained through a time consuming process, no standard earth building blocks, bricks or components are commercially available in South Africa. Unfortunately, the communal small 
scale of earth construction makes standardization difficult. This is, however, not a big obstacle as the contemporary earth buildings in the urban environment stand witness to. Standards are however, required by the decision makers, the financiers, and the builders.

In South Africa there is not only a need for low-cost building in alternative and sustainable construction methods but also for high profile buildings in the urban context [7]. Despite the absence of accredited standards and regulations the author took up this challenge and constructed his own earth house built in a post Anglo-Boer war (1899-1902) residential area of Bloemfontein. The selective use of compressed earth blocks and stabilized adobe in this small 180 square meter house is an attempt to address the status of raw earth as contemporary building material in an urban context. With some effort even the local authorities and a financial institution were convinced and approved this technology in the centre of Bloemfontein.

The Bosman residence is a second dwelling on a residential stand. In order to support the densification of the urban residential area of Westdene, Bloemfontein, a specific brown field structure was utilized. The criteria included using recycled material on site and the use of compressed earth blocks from an abandoned brickyard. A specific morphology in terms of character, volume, material and geometry was achieved. The use of plaster and paint (with colour trends from the context) and an inverted corrugated roof were in direct reaction to the existing character of the suburb of Westdene. However, a contemporary building, it attempts to blend into the context by using compressed earth blocks and adobe, while creating a high quality economic and ecologically sustainable building [3].

\section{Conclusion}

With a global network on earth construction in place for some decades now, the international community can share experiences, disseminate research findings and give advice. This support system confirms the growing rediscovery of earth as building material [13]. International as well as national workshops and conferences focused on some or other sustainable issues have converted many South African politicians, building professionals and students to the use of earth construction. The environmental friendly contemporary buildings that have been built in the past decade are the evidence. A bigger challenge still awaits the South African building industry, where more sustainable high profile buildings have to be constructed in order to have a substantial effect on the social, economic and ecological environments. The promotion of upgraded earth construction on our beautiful open plains and in our cities will continue, in order to change the image of building in earth.

\section{References}

[1] Bosman, G., Teaching Earth Architecture at the Department of Architecture at the University of the Free State: Current situation, 
Analysis and Perspective. Unpublished Thesis: Ecole D'Architecture de Grenoble, DPEA Architecture de Terre 1998-2000, pp. xv-xx. 2000.

[2] Bosman, G., Sustainability, involved ability, and the struggle for survival. Leading Architecture and Design, vol. September/ October, pp. 22-23, 2003.

[3] Bosman, G., Teaching Earth Construction in the Free State: 1995-2005. Proc. of the $4^{\text {th }}$ Conf. in the series Sustainable Built Environment, South Africa: Pretoria, pp. 38-51, 22-24 June 2005.

[4] Dayaratne, R., Earth architecture for contemporary living: prospects and new initiatives. Open House International, vol 28 no 3, pp 23-33, 2003.

[5] Gerneke. G., The return to earth: The last of three articles on earth building. Architecture SA vol July/August pp. 40-44, 1992.

[6] Houben, H., Guillaud, H., Earth Construction: A comprehensive guide. Intermediate Technology Publications, London, 1994.

[7] Jooste-Smit, P., Earth Construction: A changing tradition. Acta Structilia, 5(1\&2) pp. 55-80, 1998.

[8] Jordaan, G., Sustainable Urban Future - Cleaning up a messy Past. Proc. of the Conf Sustainable Buildings \& Integrated Design, South African Solar Academy, South Africa: Johannesburg, p. 329, $9-14$ September 2002.

[9] Noero, J., Unpublished Workshop presentation: Seven reasons why community asset management will not work. Community Asset Management (CAM) Workshop 15-16 September 2002.

[10] Norberg-Shultz, C., Genius loci - Towards a phenomenology of architecture. Academy Editions: London, pp. 5 - 30, 1984.

[11] Rodriquez, A. \& Pettus, K., The Importance of Vernacular Traditions. APT Bulletin. vol. XXII no. 3 p. 2. 1990.

[12] Steyn, J.J., The role of small local brickyards in economic development: a case study of Botchabelo, South Africa. Proc. of the annual Conf. of the Regional Studies Association, eds. S. Hardy, L. Larson \& F. Freeland, Seaford: UK, pp. 10-12, 2004.

[13] Watson, L., Earth as a British building material. Architectural design, vol 67 no. $1 \& 2$ pp. $87-89,1997$.

[14] CSIR, www.csir.co.za/boutek. 